\title{
Implementation Optimal Location and Sizing of UPFC on Iraqi Power System Grid (132 kV) Using Genetic Algorithm
}

\author{
Ghassan Abdullah Salman, Mohammed Hasan Ali, Ali Najim Abdullah \\ Department of Electrical Power and Machines, Collage of Engineering, University of Diyala, Diyala, Iraq
}

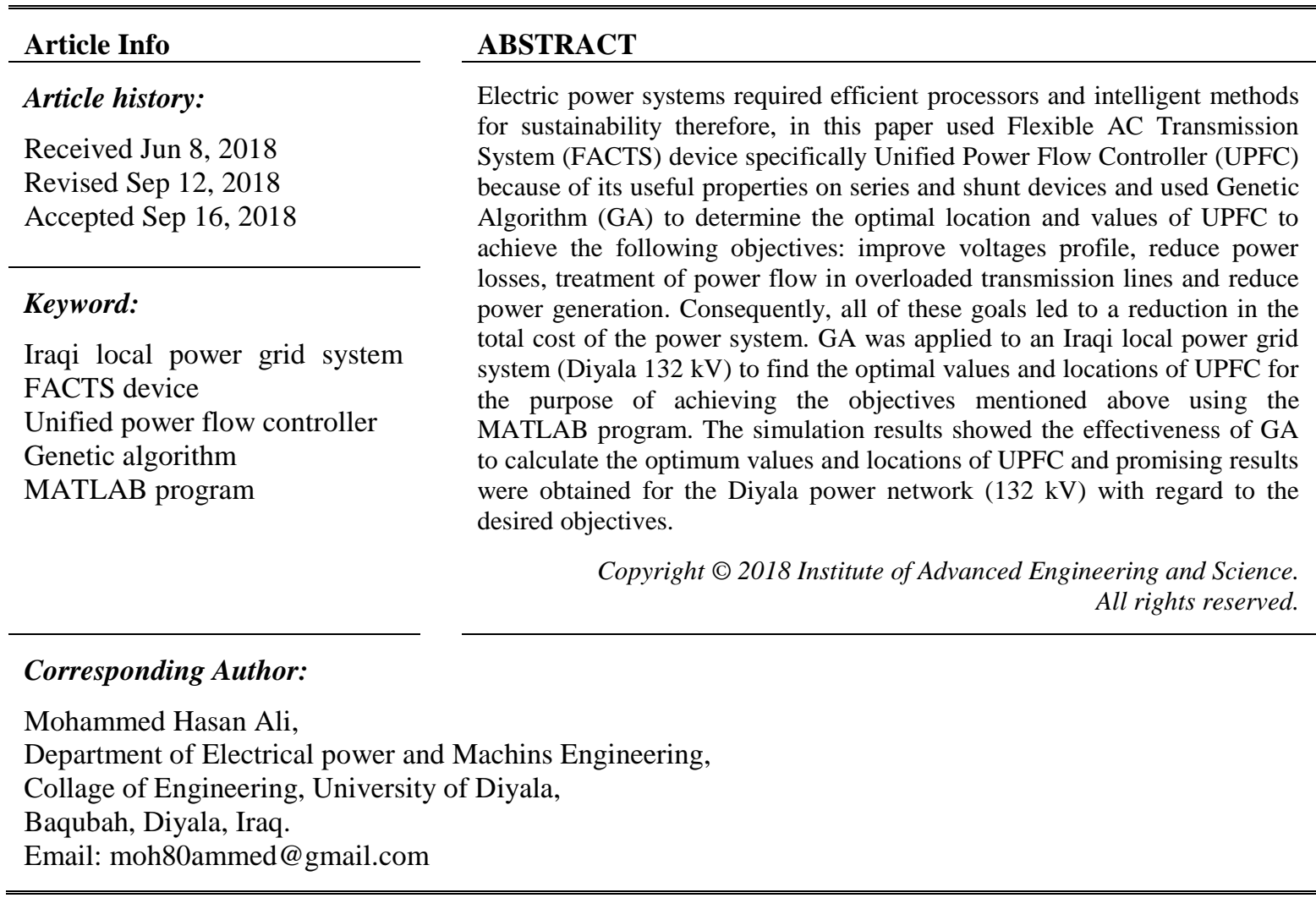

\section{INTRODUCTION}

It is important to take into consideration the increase in demand for electric power is increasing continuously, so modern systems of power networks are operating under complex pressure conditions. This complexity and increase in energy supply requires providing the system with modern control devices that help in the development of the performance of electrical networks. These FACTS devices, specifically the UPFC device, were used in the paper. One of the most powerful FACTS devices is the UPFC device because it has the advantages of both series and parallel devices belonging to the same family. Controlling the flow of active energy and reactive energy is one of the most important features of UPFCs and is effective in dealing with the disturbances occurring within the electrical system [1]-[5]. The FACTS system is remarkably and rapidly integrated with power transmission lines. It has the capability to provide the necessary boost to power transmission lines, especially the UPFC type, which consists of two self-connected converters connected with two transformers, one connected in parallel with the transmission line, while the other in series [6]-[9].

The problem of the paper lies in finding the optimal location and optimal values of the UPFC device on the local Diyala network $(132 \mathrm{kV})$ and thus improving the overall performance of the network, therefore in this paper deals with the applications of GA to find the optimal placement and setting parameter of UPFC device and its implemetation in Diyala power system network $(132 \mathrm{kV})$ to enhance the voltages profile, reduce the overall system losses, treatment of power flow in overloaded transmission lines and reduce power generation. Finally all objectives are satisfeid led to the total cost of the power system is reduced. 


\section{UNIFIED POWER FLOW CONTROLLER (UPFC)}

A simplified Basic configuration of UPFC is given in Figure 1, while the electrical model of UPFC is given in Figure 2. The principle operation of UPFC and the equations required for applying GA to it for the purpose of finding, locating and optimal sizing of the UPFC on the power transmission network (Diyala 132 $\mathrm{kV}$ ) are indicated in [4],[10]. Therefore, equations (1) to (16) are adopted to implement the GA program to reach the set targets that will be mentioned with the equations in the subsequent section.

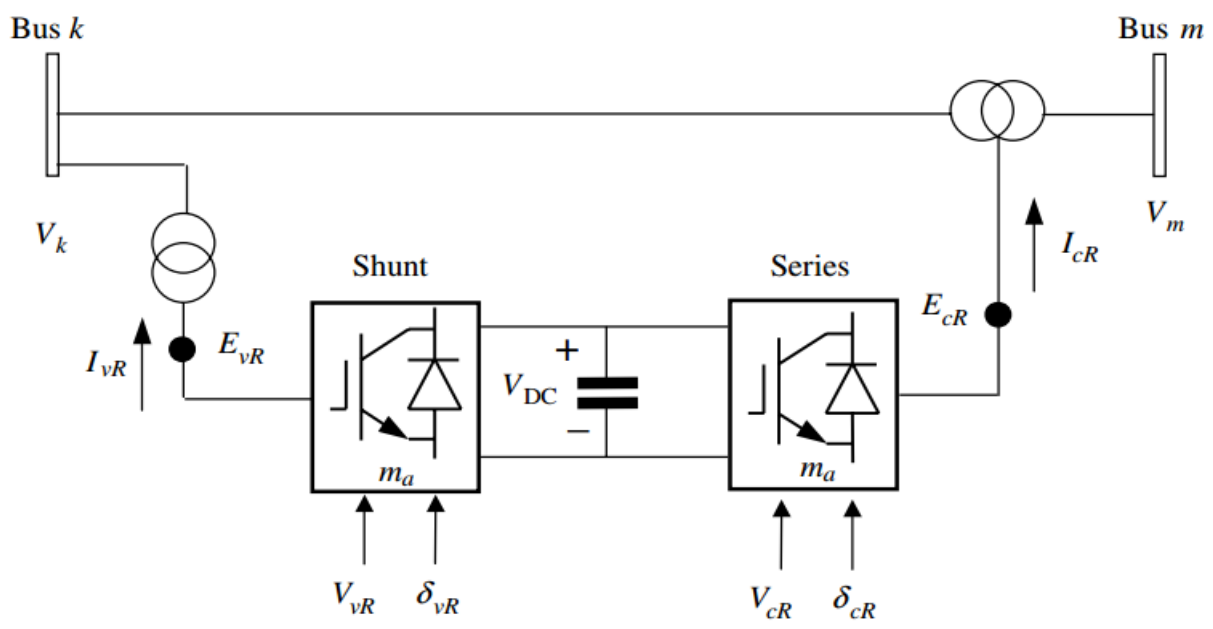

Figure 1. Basic configuration of UPFC

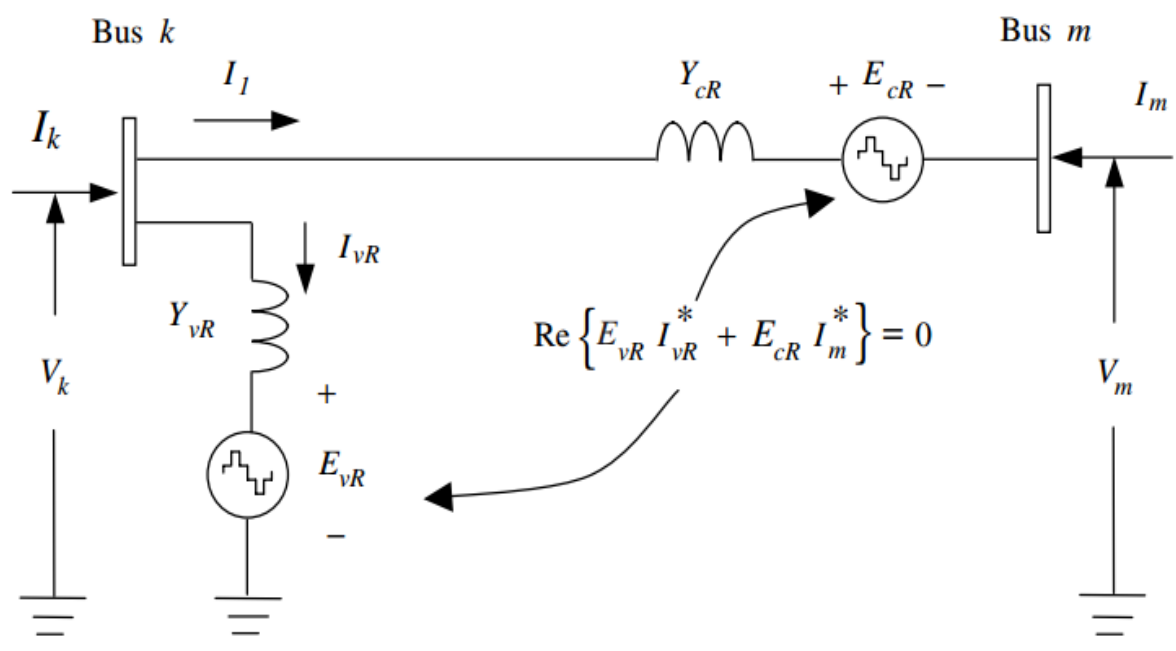

Figure 2. Electrical model of UPFC

$$
\begin{aligned}
& E_{v R}=V_{v R}\left(\cos \delta_{v R}+j \sin \delta_{v R}\right) \\
& E_{c R}=V_{c R}\left(\cos \delta_{c R}+j \sin \delta_{c R}\right) \\
& \operatorname{Re}\left\{-E_{v R} I_{v R}^{*}+E_{c R} I_{m}^{*}\right\}=0 \\
& {\left[\begin{array}{c}
\mathrm{I}_{k} \\
\mathrm{I}_{m}
\end{array}\right]=\left[\begin{array}{cccc}
\left(\mathrm{Y}_{c R}+\mathrm{Y}_{v R}\right) & -\mathrm{Y}_{c R} & -\mathrm{Y}_{c R} & -\mathrm{Y}_{v R} \\
-\mathrm{Y}_{c R} & \mathrm{Y}_{c R} & \mathrm{Y}_{c R} & 0
\end{array}\right]\left[\begin{array}{c}
\mathrm{V}_{k} \\
\mathrm{~V}_{m} \\
\mathrm{E}_{c R} \\
\mathrm{E}_{v R}
\end{array}\right]}
\end{aligned}
$$

At bus k: 


$$
\begin{aligned}
& P_{k}=V_{k}^{2} G_{k k}+V_{k} V_{m}\left[G_{k m} \cos \left(\theta_{k}-\theta_{m}\right)+B_{k m} \sin \left(\theta_{k}-\theta_{m}\right)\right]+V_{k} V_{c R}\left[G_{k m} \cos \left(\theta_{k}-\delta_{c R}\right)+\right. \\
& \left.B_{k m} \sin \left(\theta_{k}-\delta_{c R}\right)\right]+V_{k} V_{v R}\left[G_{v R} \cos \left(\theta_{k}-\delta_{v R}\right)+B_{v R} \sin \left(\theta_{k}-\delta_{v R}\right)\right] \\
& Q_{k}=-V_{k}^{2} B_{k k}+V_{k} V_{m}\left[G_{k m} \sin \left(\theta_{k}-\theta_{m}\right)-B_{k m} \cos \left(\theta_{k}-\theta_{m}\right)\right]+V_{k} V_{c R}\left[G_{k m} \sin \left(\theta_{k}-\delta_{c R}\right)-\right. \\
& \left.B_{k m} \cos \left(\theta_{k}-\delta_{c R}\right)\right]+V_{k} V_{v R}\left[G_{v R} \sin \left(\theta_{k}-\delta_{v R}\right)+B_{v R} \cos \left(\theta_{k}-\delta_{v R}\right)\right],
\end{aligned}
$$

At bus m:

$$
\begin{aligned}
& P_{m}=V_{m}^{2} G_{m m}+V_{m} V_{k}\left[G_{m k} \cos \left(\theta_{m}-\theta_{k}\right)+B_{m k} \sin \left(\theta_{m}-\theta_{k}\right)\right]+V_{m} V_{c R}\left[G_{m m} \cos \left(\theta_{m}-\delta_{c R}\right)+\right. \\
& \left.B_{m m} \sin \left(\theta_{m}-\delta_{c R}\right)\right] \\
& Q_{m}=-V_{m}^{2} B_{m m}+V_{m} V_{k}\left[G_{m k} \sin \left(\theta_{m}-\theta_{k}\right)-B_{m k} \cos \left(\theta_{m}-\theta_{k}\right)\right]+V_{m} V_{c R}\left[G_{m m} \sin \left(\theta_{m}-\delta_{c R}\right)-\right. \\
& \left.B_{m m} \cos \left(\theta_{m}-\delta_{c R}\right)\right]
\end{aligned}
$$

Series converter:

$$
\begin{aligned}
& P_{c R}=V_{c R}^{2} G_{m m}+V_{c R} V_{k}\left[G_{k m} \cos \left(\delta_{c R}-\theta_{k}\right)+B_{k m} \sin \left(\delta_{c R}-\theta_{k}\right)\right]+V_{c R} V_{m}\left[G_{m m} \cos \left(\delta_{c R}-\theta_{m}\right)+\right. \\
& \left.B_{m m} \sin \left(\delta_{c R}-\theta_{m}\right)\right] \\
& Q_{c R}=-V_{c R}^{2} B_{m m}+V_{c R} V_{k}\left[G_{k m} \sin \left(\delta_{c R}-\theta_{k}\right)-B_{k m} \cos \left(\delta_{c R}-\theta_{k}\right)\right]+V_{c R} V_{m}\left[G _ { m m } \operatorname { s i n } \left(\delta_{c R}-\right.\right. \\
& \left.\left.\theta_{m}\right)-B_{m m} \cos \left(\delta_{c R}-\theta_{m}\right)\right]
\end{aligned}
$$

Shunt converter:

$$
\begin{aligned}
& P_{v R}=-V_{v R}^{2} G_{v R}+V_{v R} V_{k}\left[G_{v R} \cos \left(\delta_{v R}-\theta_{k}\right)+B_{v R} \sin \left(\delta_{v R}-\theta_{k}\right)\right] \\
& Q_{v R}=V_{v R}^{2} B_{v R}+V_{v R} V_{k}\left[G_{v R} \sin \left(\delta_{v R}-\theta_{k}\right)-B_{v R} \cos \left(\delta_{v R}-\theta_{k}\right)\right] \\
& \Delta P_{b b}=P_{v R}+P_{c R}=0 \\
& P_{v R}+P_{c R}=P_{k}+P_{m}=0
\end{aligned}
$$$$
\left[\begin{array}{c}
\Delta P_{k} \\
\Delta P_{m} \\
\Delta Q_{k} \\
\Delta Q_{m} \\
\Delta P_{m k} \\
\Delta Q_{m k} \\
\Delta P_{b b}
\end{array}\right]=\left[\begin{array}{ccccccc}
\frac{\partial P_{k}}{\partial \theta_{k}} & \frac{\partial P_{k}}{\partial \theta_{m}} & \frac{\partial P_{k}}{\partial V_{v R}} V_{v R} & \frac{\partial P_{k}}{\partial V_{m}} V_{m} & \frac{\partial P_{k}}{\partial \delta_{c R}} & \frac{\partial P_{k}}{\partial V_{c R}} V_{c R} & \frac{\partial P_{k}}{\partial \delta_{v R}} \\
\frac{\partial P_{m}}{\partial \theta_{k}} & \frac{\partial P_{m}}{\partial \theta_{m}} & 0 & \frac{\partial P_{m}}{\partial V_{m}} V_{m} & \frac{\partial P_{m}}{\partial \delta_{c R}} & \frac{\partial P_{m}}{\partial V_{c R}} V_{c R} & 0 \\
\frac{\partial Q_{k}}{\partial \theta_{k}} & \frac{\partial Q_{k}}{\partial \theta_{m}} & \frac{\partial Q_{k}}{\partial V_{v R}} V_{v R} & \frac{\partial Q_{k}}{\partial V_{m}} V_{m} & \frac{\partial Q_{k}}{\partial \delta_{c R}} & \frac{\partial Q_{k}}{\partial V_{c R}} V_{c R} & \frac{\partial Q_{k}}{\partial \delta_{v R}} \\
\frac{\partial Q_{m}}{\partial \theta_{k}} & \frac{\partial Q_{m}}{\partial \theta_{m}} & 0 & \frac{\partial Q_{m}}{\partial V_{m}} V_{m} & \frac{\partial Q_{m}}{\partial \delta_{c R}} & \frac{\partial Q_{m}}{\partial V_{c R}} V_{c R} & 0 \\
\frac{\partial P_{m k}}{\partial \theta_{k}} & \frac{\partial P_{m k}}{\partial \theta_{m}} & 0 & \frac{\partial P_{m k}}{\partial V_{m}} V_{m} & \frac{\partial P_{m k}}{\partial \delta_{c R}} & \frac{\partial P_{m k}}{\partial V_{c R}} V_{c R} & 0 \\
\frac{\partial Q_{m k}}{\partial \theta_{k}} & \frac{\partial Q_{m k}}{\partial \theta_{m}} & 0 & \frac{\partial Q_{m k}}{\partial V_{m}} V_{m} & \frac{\partial Q_{m k}}{\partial \delta_{c R}} & \frac{\partial Q_{m k}}{\partial V_{c R}} V_{c R} & 0 \\
\frac{\partial P_{b b}}{\partial \theta_{k}} & \frac{\partial P_{b b}}{\partial \theta_{m}} & \frac{\partial P_{b b}}{\partial V_{v R}} V_{v R} & \frac{\partial P_{b b}}{\partial V_{m}} V_{m} & \frac{\partial P_{b b}}{\partial \delta_{c R}} & \frac{\partial P_{b b}}{\partial V_{c R}} V_{c R} & \frac{\partial P_{b b}}{\partial \delta_{v R}}
\end{array}\right]\left[\begin{array}{c}
\Delta \theta_{k} \\
\Delta \theta_{m} \\
\frac{\Delta V_{v R}}{V_{v R}} \\
\frac{\Delta V_{m}}{V_{m}} \\
\Delta \delta_{c R} \\
\frac{\Delta V_{c R}}{V_{c R}} \\
\Delta \delta_{v R}
\end{array}\right]
$$

$$
\left[\begin{array}{c}
\Delta P_{k} \\
\Delta P_{m} \\
\Delta Q_{k} \\
\Delta Q_{m} \\
\Delta P_{m k} \\
\Delta Q_{m k} \\
\Delta P_{b b}
\end{array}\right]=\left[\begin{array}{ccccccc}
\frac{\partial P_{k}}{\partial \theta_{k}} & \frac{\partial P_{k}}{\partial \theta_{m}} & \frac{\partial P_{k}}{\partial V_{k}} V_{k} & \frac{\partial P_{k}}{\partial V_{m}} V_{m} & \frac{\partial P_{k}}{\partial \delta_{c R}} & \frac{\partial P_{k}}{\partial V_{c R}} V_{c R} & \frac{\partial P_{k}}{\partial \delta_{v R}} \\
\frac{\partial P_{m}}{\partial \theta_{k}} & \frac{\partial P_{m}}{\partial \theta_{m}} & \frac{\partial P_{m}}{\partial V_{k}} V_{k} & \frac{\partial P_{m}}{\partial V_{m}} V_{m} & \frac{\partial P_{m}}{\partial \delta_{c R}} & \frac{\partial P_{m}}{\partial V_{c R}} V_{c R} & 0 \\
\frac{\partial Q_{k}}{\partial \theta_{k}} & \frac{\partial Q_{k}}{\partial \theta_{m}} & \frac{\partial Q_{k}}{\partial V_{k}} V_{k} & \frac{\partial Q_{k}}{\partial V_{m}} V_{m} & \frac{\partial Q_{k}}{\partial \delta_{c R}} & \frac{\partial Q_{k}}{\partial V_{c R}} V_{c R} & \frac{\partial Q_{k}}{\partial \delta_{v R}} \\
\frac{\partial Q_{m}}{\partial \theta_{k}} & \frac{\partial Q_{m}}{\partial \theta_{m}} & \frac{\partial Q_{m}}{\partial V_{k}} V_{k} & \frac{\partial Q_{m}}{\partial V_{m}} V_{m} & \frac{\partial Q_{m}}{\partial \delta_{c R}} & \frac{\partial Q_{m}}{\partial V_{c R}} V_{c R} & 0 \\
\frac{\partial P_{m k}}{\partial \theta_{k}} & \frac{\partial P_{m k}}{\partial \theta_{m}} & \frac{\partial P_{m k}}{\partial V_{k}} V_{k} & \frac{\partial P_{m k}}{\partial V_{m}} V_{m} & \frac{\partial P_{m k}}{\partial \delta_{c R}} & \frac{\partial P_{m k}}{\partial V_{c R}} V_{c R} & 0 \\
\frac{\partial Q_{m k}}{\partial \theta_{k}} & \frac{\partial Q_{m k}}{\partial \theta_{m}} & \frac{\partial Q_{m k}}{\partial V_{k}} V_{k} & \frac{\partial Q_{m k}}{\partial V_{m}} V_{m} & \frac{\partial Q_{m k}}{\partial \delta_{c R}} & \frac{\partial Q_{m k}}{\partial V_{c R}} V_{c R} & 0 \\
\frac{\partial P_{b b}}{\partial \theta_{k}} & \frac{\partial P_{b b}}{\partial \theta_{m}} & \frac{\partial P_{b b}}{\partial V_{k}} V_{k} & \frac{\partial P_{b b}}{\partial V_{m}} V_{m} & \frac{\partial P_{b b}}{\partial \delta_{c R}} & \frac{\partial P_{b b}}{\partial V_{c R}} V_{c R} & \frac{\partial P_{b b}}{\partial \delta_{v R}}
\end{array}\right]\left[\begin{array}{c}
\Delta \theta_{k} \\
\Delta \theta_{m} \\
\frac{\Delta V_{k}}{V_{k}} \\
\frac{\Delta V_{m}}{V_{m}} \\
\Delta \delta_{c R} \\
\frac{\Delta V_{c R}}{V_{c R}} \\
\Delta \delta_{v R}
\end{array}\right]
$$




\section{GENETIC ALGORITHM (GA)}

Based on the fundamentals of genetics and natural selection, GA is applied for optimal search. GA allows, according to specific and specific rules, to create a group of individuals consisting of many individuals who reduce the target function [11]-[13]. One of GA's primary priorities is to build on the principles of natural evolution and GA is applied to find a solution from a set of solutions in three key steps to calculate the objective function which is:

1. Selection: - Each individual is repeated at this stage with the relative probability of the target and commensurate with the population.

2. Crossover: - Two new offspring are produced by combining two parents in a randomly selected way by dividing the first generation into two parts. This leads to the new offspring replacing the parents generation in the population.

3. Mutation: - The best solutions are taken from the individual after changing the values on the sites randomly, which are individuals after a constant iteration of the preparation of the algorithm during the operating period.

In this paper, the objectives function is formulated to determine optimal location and sizing of UPFC device. The objectives function are followed below to reduced voltage deviation (load buses), minimized the overall system losses (active and reactive power) and reduced the power flow in overloaded lines.

\subsection{Voltage Deviation (VD)}

The voltage deviation at each load bus shall be as small as possible for the purpose of achieving good voltage performance [14],[15]. The voltage deviation equation can be represented as follows:

$$
V D=\sum_{i=1}^{n P Q}\left|V_{i}-1\right|^{2}
$$

\subsection{Active and Reactive Power Loss}

The goal of reducing active and reactive power loss is achieved by choosing the best combination of variables, which minimizes the total power loss of network system at the same time as all network constraints [14],[15]. The active and reactive power loss equations can be represented as follows:

$$
\begin{aligned}
& P_{L}=\sum_{i=1}^{N_{L}} G_{i}\left(V_{k}^{2}+V_{m}^{2}-2 V_{k} V_{m} \cos \left(\delta_{k}-\delta_{m}\right)\right) \\
& Q_{L}=\sum_{i=1}^{N_{L}} B_{i}\left(V_{k}^{2}+V_{m}^{2}-2 V_{k} V_{m} \sin \left(\delta_{k}-\delta_{m}\right)\right)
\end{aligned}
$$

\subsection{Power Flow in Overloaded Lines}

This goal is calculated for each line of the power system network. To satisfied this objective the lines should be loaded less than $100 \%$ [14],[15]. The active and reactive power flow in transmission lines can be express by equations as follows:

$$
\begin{aligned}
& P_{G k}-P_{D k}=V_{k} \sum_{i=1}^{N_{B}} V_{m}\left[G_{i} \cos \left(\delta_{k}-\delta_{m}\right)+B_{i} \sin \left(\delta_{k}-\delta_{m}\right)\right] \\
& Q_{G k}-Q_{D k}=V_{k} \sum_{i=1}^{N_{B}} V_{m}\left[G_{i} \sin \left(\delta_{k}-\delta_{m}\right)+B_{i} \cos \left(\delta_{k}-\delta_{m}\right)\right]
\end{aligned}
$$
steps below:

The GA for the optimal location and sizig of UPFC device on Diyala 10 bus $(132 \mathrm{kV})$ is given in

Step 1 : Initialize the population size of GA and the parameters of UPFC device.

Step 2 : Run the program of power flow (Newton Raphson).

Step 3 : For all the individuals objective values are calculated.

Step 4 : Based on the objective values, select a new population from the old population based on the calculation function.

Step 5 : GA operators, crossover and mutation are applied to the population that has been selected to create new solutions.

Step 6 : For new chromosomes the objective values are calculated and using it into the population.

Step 7 : If the time done, stop GA program and print the best individual, while if not go to step 4. 


\section{RESULTS AND DISCUSSION}

As a result of the development of electrical power systems and the increase in the demand for load, it is necessary to develop the performance of electric transmission networks in multiple ways to suit all possible changes. Studies dealing with such a development in electrical systems are many and have developed effective solutions to correct the required changes. However, this paper deals with the realistic network (Diyala $132 \mathrm{kV}$ ), as presented in the papers [9],[14]. In this paper, the GA was applied for the purpose of applying the optimum site and the optimal size of the UPFC device on the Diyala grid power system, this is another feature that was not in the papers [9],[14].

In this paper, the best location and the best size of the UPFC device were determined by using the GA as shown in Table 1, depending on the three objective goals and then explaining the three objectives in different Tables and Figures separately.

Table 1. GA results for optimal UPFC

\begin{tabular}{ccc}
\hline Line Name & Series VSC value $\left(\mathrm{V}_{c R}\right)$ & Sunt VSC value $\left(\mathrm{V}_{v R}\right)$ \\
\hline ZERBIL-KNKN & 0.1221 & 0.9357 \\
DAL3-BQBW & 0.4418 & 0.8479 \\
\hline
\end{tabular}

Table 2 shows the effect of UPFC device on the Diyala electric network (10 bus $132 \mathrm{kV}$ ) so as to improve both the voltages of buses and the phase angle and then reduced the voltage deviation from $3.521 *$ $10^{-3}$ before adding UPFC device to $2.408 * 10^{-3}$ after adding UPFC device. The voltage deviation is obtained on the basis of equation 17 through the results given in Table 2 .

Table 2. Voltages of 10 bus $132 \mathrm{kV}$ (Diyala-Iraq)

\begin{tabular}{ccccc}
\hline \multirow{2}{*}{ Bus Name } & \multicolumn{2}{c}{ Voltage $(\mathrm{p} . u)$} & \multicolumn{2}{c}{ Phase Angle (rad) } \\
& Without UPFC & With UPFC & Without UPFC & With UPFC \\
\hline DAL3 & 1.04 & 1.04 & 0 & 0 \\
ZERBIL & 1.03 & 1.03 & 0.20925 & 0.16422 \\
HMRH & 1.025 & 1.025 & 0.02708 & 0.02564 \\
KALS & 1.0342 & 1.0342 & -0.00496 & -0.00496 \\
BQBW & 1.0039 & 1.0305 & -0.00883 & -0.00741 \\
BLDZ & 0.99296 & 0.99296 & -0.04412 & -0.04412 \\
HMRN & 1.0023 & 1.0108 & 0.03509 & 0.03114 \\
KNKN & 0.96002 & 1.0105 & 0.06968 & 0.06465 \\
MQDA & 0.98166 & 1.0051 & 0.02388 & 0.02192 \\
BQBE & 0.98137 & 0.99757 & -0.01584 & -0.01521 \\
\hline
\end{tabular}

Figure 3 shows the loading of the lines before the addition of the UPFC device, observed that the lines between the DAL3 - BQBW, KNKN - ZERBIL and BQBW - BQBE up to the maximum degrees of the overloading and in particular line DAL3 - BQBW more than 100\%. While Figure 4 shows the loading of the same lines after the addition of UPFC device, where observed the reduction of the loading rate to less than $80 \%$. This difference, which is approximately $20 \%$ of the load before and after the addition of the UPFC device, is a big gain in energy and thus reducing the stress on the lines overloaded by the permissible limits. 


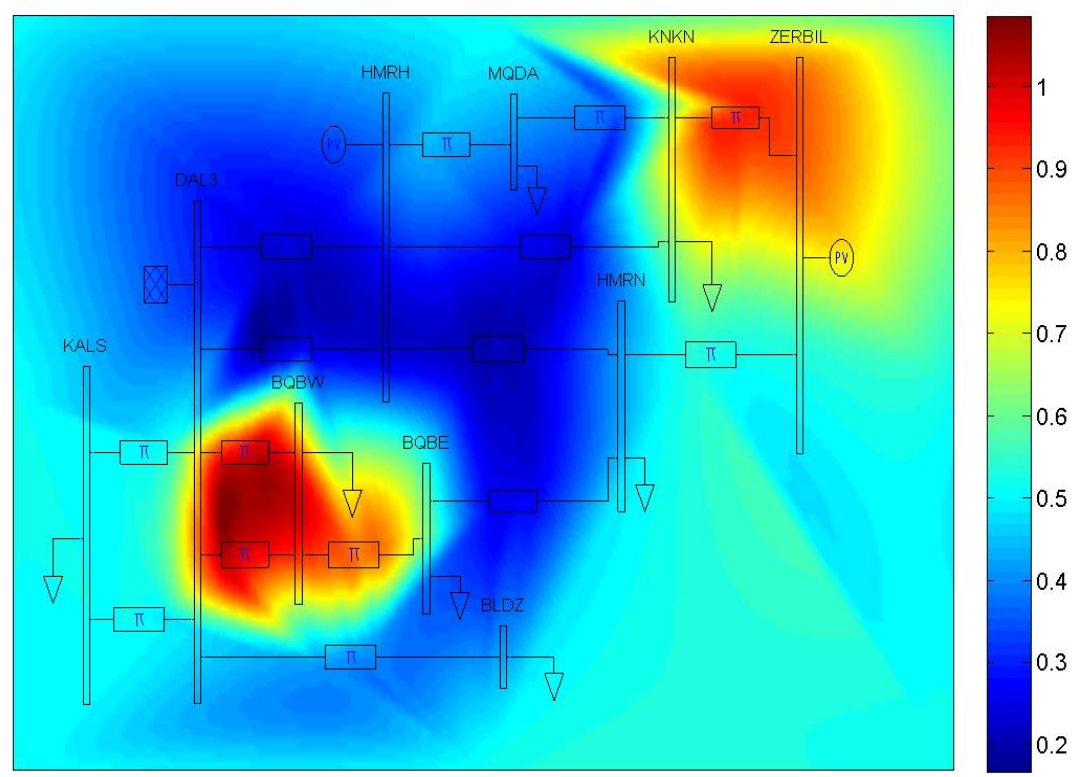

Figure 3. Power flow in transmission lines without UPFC

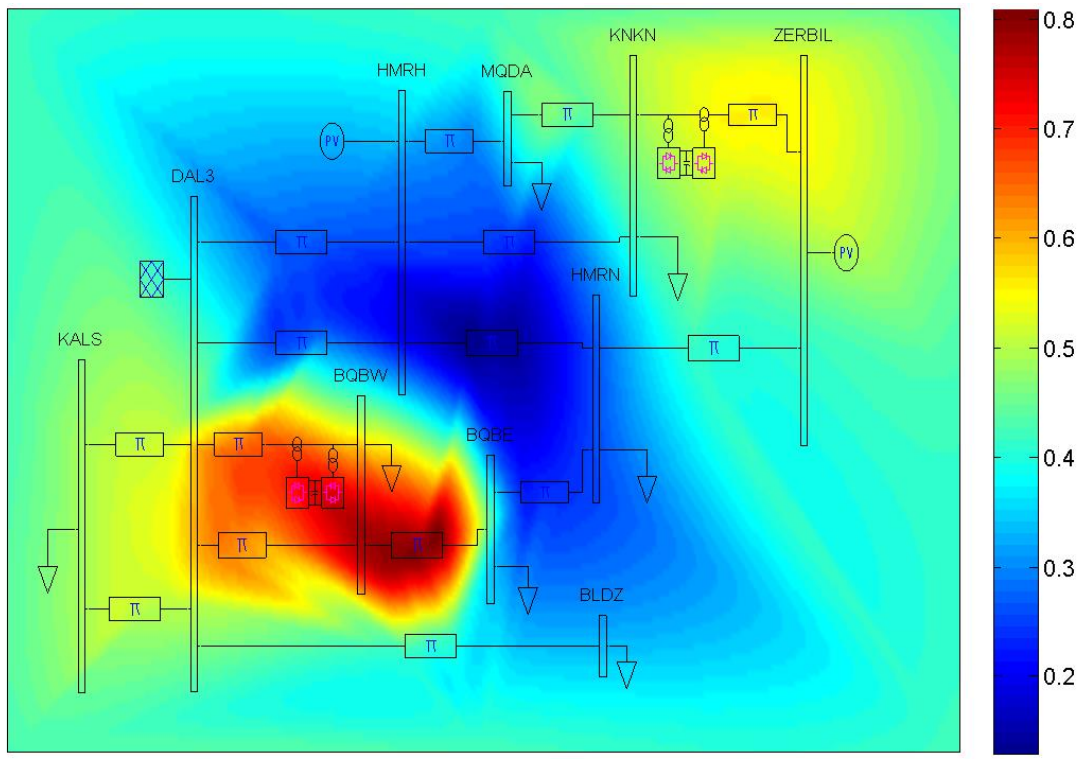

Figure 4. Power flow in transmission lines with UPFC

Figure 5 shows the generation of real power and reactive power without and with UPFC device, so that the real power generation is reduced by $4.743 \mathrm{MW}$ while the reactive power generation is reduced by 7.815 MVAR. while the real power losses and reactive power losses were shown in Figure 6 without and with UPFC device, so that the real power losses is reduced by $4.743 \mathrm{MW}$ while the reactive power losses is reduced by 7.815 MVAR. observed that the reduction in losses is offset by reduction in generation and this achieves balance in power system. As a result, the cost of power generation will also decrease. 


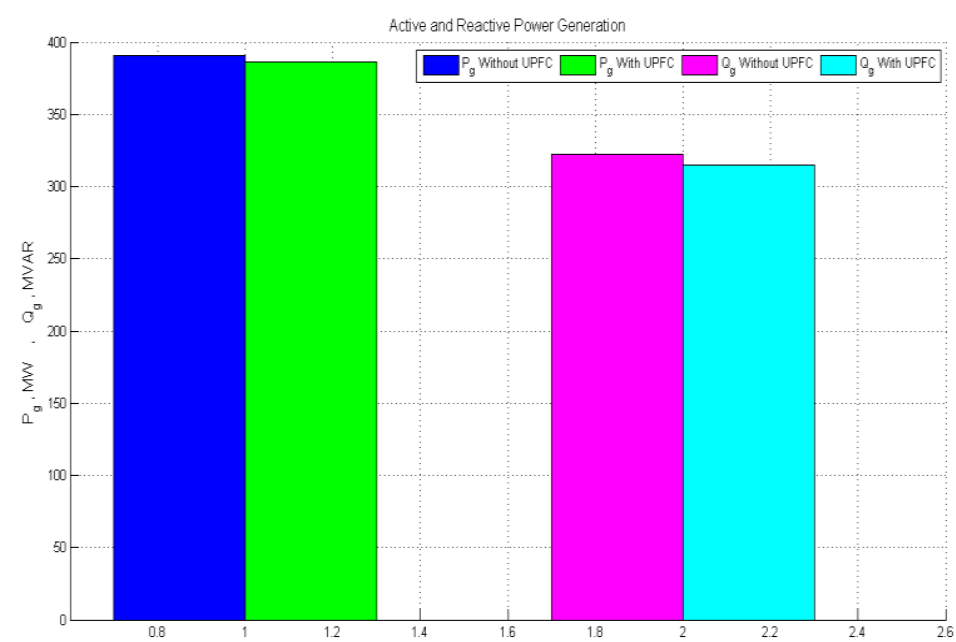

Figure 5. Active and reactive power generation in 10 bus $132 \mathrm{kV}$ (Diyala-Iraq)

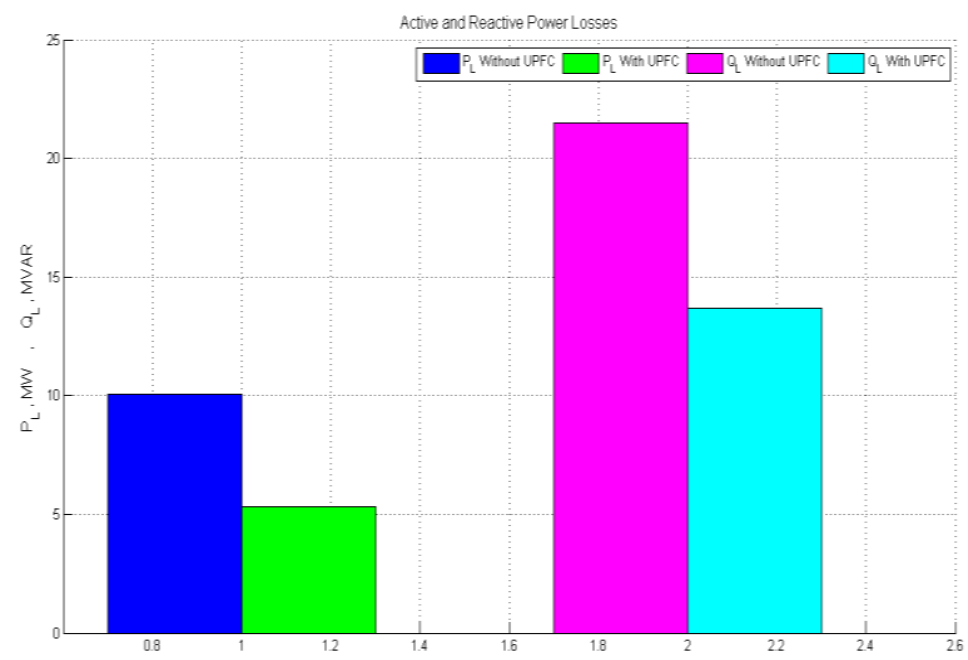

Figure 6. Active and reactive power losses in 10 bus $132 \mathrm{kV}$ (Diyala-Iraq)

Finally, proved that the application of UPFC device by using GA yields impressive results, improves the performance and efficiency of the Diyala electric network $(132 \mathrm{kV})$ compared with the references [9] and [14], achieves all the desired objectives functions and gives high control over the real and reactive power flow in transmission lines through the composite (series-parallel) for UPFC.

\section{CONCLUSION}

The UPFC device cannot be implemented at any location of the power system network because in some locations its impact is undesirable on the electric power system. In this paper utilize a GA to find the optimal location and sizing of UPFC device for satisfied the objectives function: minimize the overall system losses active and reactive power, treatment of power flow in overloaded transmission lines, the load voltage deviation is reduced therefore improve voltages profile, minimize power generation therefore the cost of the power system network is reduced and consequently improve the overall performance of Diyala 10 bus power system grid $(132 \mathrm{kV})$. The optimal location and parameter setting of UPFC device is determined using GA based on MATLAB program, the lines (DAL3-BQBW) and (ZERBIL-KNKN) represent the optimal locations to placement UPFC device. This paper represent the first work applied optimization technique (GA) to find the optimal placement and setting of UPFC device on local power system grid ( Diyala 10 bus 132 $\mathrm{kV}$ ). Future work will can be use another optimization techniques to determine the optimal location and sizing of UPFC or other types of FACTS devices. 


\section{ACKNOWLEDGEMENTS}

The authors would like to thank Mr. Abdulrazzaq F. Noori for his valuable suggestions and help him implement the MATLAB program to find optimal values using the genetic algorithm on the Iraqi electrical system grid to show the paper in this format and to meet all the requirements of the work.

\section{REFERENCES}

[1] M. Zadehbagheri, et al., "Review of the UPFC Different Models in Recent Years," International Journal of Power Electronics and Drive System (IJPEDS), vol/issue: 4(3), pp. 343-355, 2014.

[2] Radu, et al., "A multi-objective genetic algorithm approach to optimal allocation of multi-type FACTS devices for power systems security," Power Engineering Society General Meeting, IEEE, 2006.

[3] N. G. Hingorani, "Power electronics in electrical utilities: role of power electronics in future power systems," Proc. of the IEEE, vol/issue: 76(4), pp. 481-482, 1988.

[4] E. Acha, et al., "FACTS Modeling and Simulation in Power Networks," John Wiley and Sons LTD, England, 2004.

[5] M. Packiasudha and S. Suja, "FACT Device for Reactive Power Compensation in the Deregulated Electrical Power Environmnt," International Journal of Power Electronics and Drive System (IJPEDS), vol/issue: 6(4), pp. 730-735, 2015.

[6] N. G. Hingorani and L. Gyugyi, "Understanding FACTS Concepts and Technology of Flexible AC Transmission Systems,” New York: IEEE Press, 2000.

[7] S. R. Samantaray, "A Data-Mining Model for Protection of FACTS-Based Transmission Line," IEEE Transactions on Power Delivery, vol/issue: 28(2), pp. 612-618, 2013.

[8] S. K Mishra, et al., "Fault Detection \& Classification in UPFC Integrated Transmission Line Using DWT," International Journal of Power Electronics and Drive System (IJPEDS), vol/issue: 8(4), pp. 1793-1803, 2017.

[9] H. I. Hussein, et al., "Phase Measurement Units based FACT's Devices for the Improvement of Power Systems Networks Controllability," International Journal of Electrical and Computer Engineering (IJECE), vol/issue: 8(2), pp. 888-899, 2018.

[10] A. F. Noori, "Enhancement of Voltage and Rotor Angle Stability for INSGS Using UPFC Devices," M.Sc. thesis, University of Technology, Iraq, 2012.

[11] G. A. Salman, "Automatic Generation Control in Multi Area Interconnected Power System Using PID Controller Based on GA and PSO," Second Engineering Scientific Conference, College of Engineering, University of Diyala, pp. 297-310, 2015.

[12] I. Azim and F. Rahman, "Genetic Algorithm Based Reactive Power Management by SVC," International Journal of Electrical and Computer Engineering (IJECE), vol/issue: 4(2), pp. 200-206, 2014.

[13] P. C. Ramaswamy and G. Deconinck, "Smart Grid Reconfiguration Using Simple Genetic Algorithm and NSGAII," $3^{\text {rd }}$ IEEE PES Smart Grid Technologies Europe (ISGT Europe), Berlin, 2012.

[14] G. A. Salman, "Implementation SVC and TCSC to Improvement the Efficacy of Diyala Electric Network (132 kV)," American Journal of Engineering Research (AJER), vol/issue: 4(5), pp. 163-170, 2015.

[15] B. P. Saoji and A. P. Vaidya, "Hypothetical Study For Selection Of Optimal Location Of Multiple FACTS Devices Under Contingent Condition Using Different Objective Functions," Electrical and Electronics Engineering: An International Journal (ELELIJ), vol/issue: 2(4), pp. 71-86, 2013.

\section{BIOGRAPHIES OF AUTHORS}

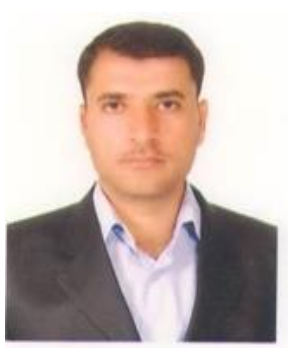

Ghassan Abdullah Salman was born in Diyala, Iraq, in 1983, received his B.Sc. from University Diyala / Iraq in 2006, M. Sc. from university of technology, Baghdad, Iraq in 2011. He is currently senior lecturer in the Department of Electrical Power Engineering, College of Engineering, University of Diyala Iraq. He has three years of Industrial experience and electrical companies and has teaching experience. His research interests are optimal power system, power system operation and control, FACTS devices, power system security and power Quality. He has 6 published papers.

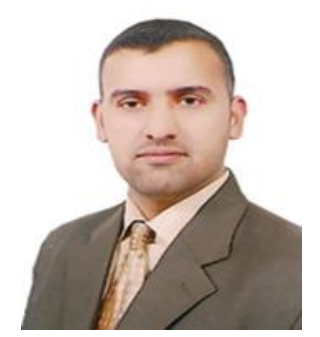

Mohammed Hasan Ali was born in Diyala, Iraq, in 1981, received his B.Sc. from University Diyala / Iraq in 2006, M. Sc. from University of Belgorod , Russia ,2013 .He is currently assistant lecturer at the Department of Electrical Power Engineering, College of Engineering, University of Diyala Iraq. Professional Strength and Skills: His current research interests are power system modeling, power quality, renewable energy and power electronics. He has 10 years experience in practice of Electrical engineering. He is teaching several basic subjects of the Electrical Engineering, University of Diyala Iraq. He has 4 published papers. 


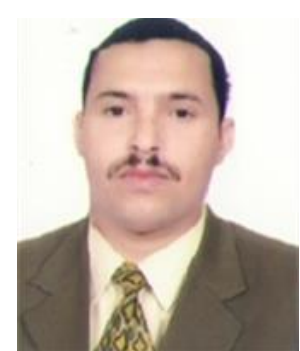

Ali Najim Abdullah was born in Diyala, Iraq, in 1980, received his B.Sc. from University Diyala / Iraq in 2003, M. Sc. from University of Belgorod, Russia, 2013. He is currently assistant lecturer at the Department of Electrical Power Engineering, College of Engineering, University of Diyala Iraq. Professional Strength and Skills: His current research interests are power system modeling, power quality, power stability, power reliability, renewable energy, electrical machine. He has 10 years experience in practice of Electrical engineering. He is teaching several basic subjects of the Electrical Engineering, University of Diyala Iraq. He has 2 published papers. 